\title{
O NOVO PADRÃO DE DESENVOLVIMENTO AGROINDUSTRIAL E A ATUAÇÃO DAS COOPERATIVAS AGROPECUÁRIAS NO PARANÁ ${ }^{1}$ \\ The new pattern of the agroindustrial development and the cooperatives in the Paraná state
}

\author{
Sergio FAJARDO
}

\section{RESUMO}

O artigo discute as transformações no setor agroindustrial pela via cooperativista a partir dos anos de 1970. Consideradas como agentes ativos no processo de modernização da agricultura paranaense, as cooperativas desempenharam também importante papel na reestruturação produtiva do Estado do Paraná ao adentrarem às atividades agroindustriais. A verticalização representou um salto no crescimento das cooperativas que atuam no meio rural, mas acabou implicando num redirecionamento das estratégias das cooperativas, que passaram a atuar num mercado extremamente competitivo.

\section{Palavras-chave:}

Cooperativas paranaenses; setor agroindustrial; economia paranaense.

\begin{abstract}
This article aims at discussing the transformations in the cooperativist rural sector in the state of Paraná since 1970. Considerable active agents in the process of modernization in the agriculture from Paraná, the cooperatives developed also an important role in the productive restructuralization in the State of Paraná, when they started the agroindustrial activities. The verticalization represented a big growth of the cooperatives that act in the rural area, but it also implied in a redirection of the cooperatives' strategies, that started acting in an extremely competitive market.
\end{abstract}

\section{Key Words:}

Paraná cooperatives; agroindustrial section, economy from Paraná.

${ }^{1} \mathrm{O}$ artigo é resultado de parte da pesquisa desenvolvida durante o curso de Mestrado em Geografia pela Universidade estadual de Maringá - PR, cuja Dissertação foi defendida pelo autor em março de 2000.

${ }^{2}$ Professor do Departamento de Geografia da Unicentro, em Guarapuava-PR; Doutorando em Geografia pela FCT/UNESP, Campus de Presidente Prudente - SP. 


\section{INTRODUÇÃO}

A proposta no presente artigo é estabelecer uma breve discussão em torno da conformação de um novo padrão de desenvolvimento agroindustrial no Brasil a partir, sobretudo, da década de 1970. Mais especificamente a participação das cooperativas agropecuárias paranaenses no processo é evidenciada.

Com o estrondoso crescimento de algumas cooperativas do ramo agropecuário no Paraná, aquelas que buscaram na verticalização uma aposta à agregação do valor na produção recebida e comercializada pelos produtores associados, encontram no êxito desses propósitos uma situação peculiar: atuar ao mesmo tempo enquanto entidade associativa e grande empresa capitalista. Alguns aspectos essenciais presentes nos ideais fundadores do cooperativismo passam a ser questionados devido à discrepância existente nas duas faces das chamadas cooperativas agroindustriais.

Por outro lado, não se pode negar que no Estado do Paraná a atuação das cooperativas agropecuárias nas últimas três décadas foi sobremodo importante na reestruturação produtiva do espaço regional. As cooperativas representaram o setor mais significativo dentro das iniciativas de investimentos agroindustriais paranaenses. A produção agropecuária, acompanhando o processo, é modernizada e diversificada por meio dos direcionamentos conduzidos pelas cooperativas ao lado, obviamente, de outras grandes empresas do setor agroindustrial.

\section{A INTEGRAÇÃO DAS COOPERATIVAS PARANAENSES}

Visando dar um novo impulso às cooperativas, em 1969 têm início no Paraná as primeiras discussões em torno da implantação dos projetos de integração numa ação coordenada conjuntamente entre os vários órgãos promotores do cooperativismo (OCEPAR, 1997, p. 5). Os projetos buscavam rediscutir a forma de atuação das cooperativas. Tratava-se de uma reordenação estratégica. Era preciso que a atuação das cooperativas fosse pensada e organizada de modo que prevalecesse a harmonia do conjunto das cooperativas, evitando concorrência entre as mesmas (pela delimitação das áreas de atuação de cada cooperativa).

Essa reestruturação organizacional das cooperativas se concretizou com instalação dos Projetos de Integração Cooperativista a partir de 1971. O Paraná foi dividido em três grandes áreas (Figura 1), cada uma relativa a um projeto. São eles: o Projeto Iguaçu de Cooperativismo - PIC, criado em 1974, abrangendo o Oeste e Sudoeste; o Projeto Norte de Cooperativismo NORCOOP, implantado em 1974, cobrindo todo o Norte e parte do centro do Estado; enquanto o Projeto Sul de Cooperativismo - SULCOOP, que teve início em 1976, era responsável pela região Centro-sul. A própria Organização das Cooperativas do Paraná - OCEPAR, nasceu nesse período como órgão que apoiou a execução dos projetos, constituindo-se na entidade representativa dos interesses das cooperativas paranaenses (OCEPAR, 1997).

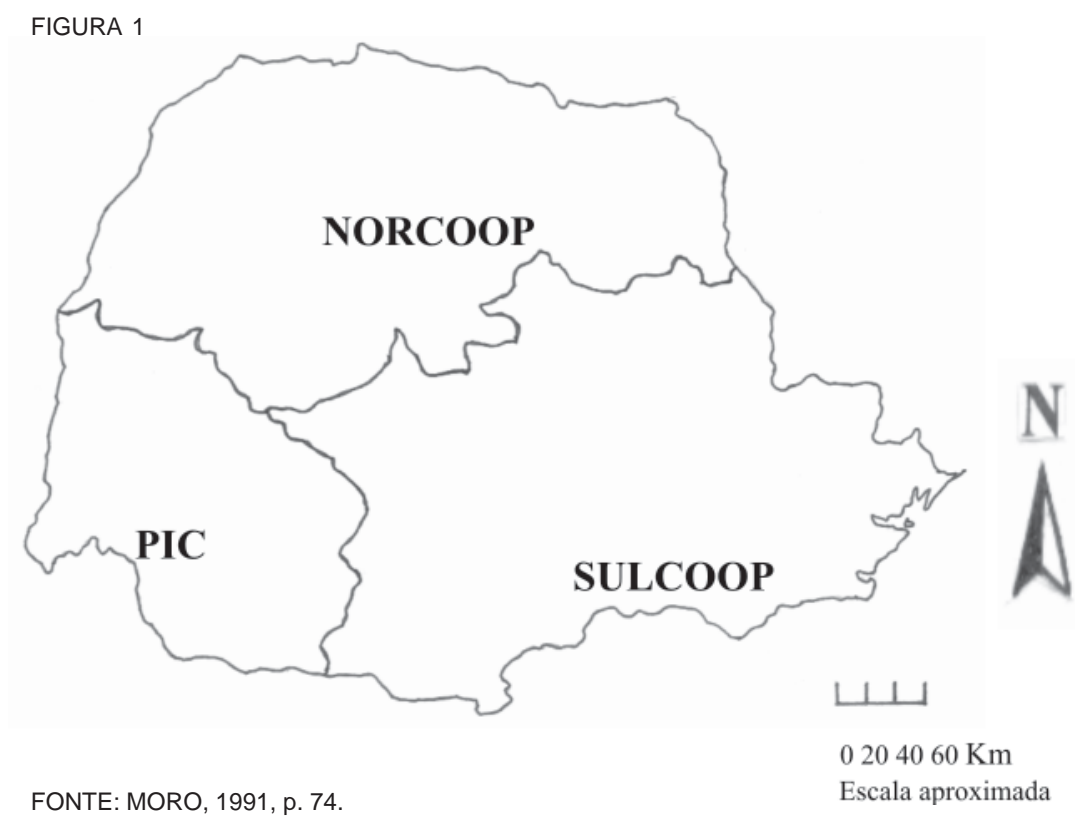




\section{ÁREAS DE ATUAÇÃO ${ }^{3}$ DOS PROJETOS REGIONAIS DE COOPERATIVISMO NO PARANÁ}

O crescimento das cooperativas no setor agroindustrial, ou seja, no seu processo de verticalização, foi alcançado graças também aos projetos de integração definidos no início da década de 70 . Estes representaram uma reestruturação econômica e filosófica do cooperativismo paranaense. Essa forma de organização permitiu um desenvolvimento das cooperativas de maneira "dirigida"; os próprios investimentos em agroindustrialização passavam a ser impulsionados de maneira planejada.

Tal integração possibilitou uma participação mais
efetiva das cooperativas na economia estadual, em
função da agregação dos interesses dos produtores
rurais paranaenses, permitindo a concretização da
montagem de uma infra-estrutura básica para o aten-
dimento de crescente produção estadual e de funda-
mental importância para o início da integração verti-
cal a agroindustrialização. Significa dizer que, a partir
da organização da produção agrícola, as cooperati-
vas agropecuárias passaram a preocupar-se com a
montagem do Complexo Agroindustrial, não se con-
formando com a condição de meras repassadoras
de matérias-primas as indústrias. (OCEPAR, 1997,
p.5).

Com a consolidação da integração das cooperativas, o objetivo das mesmas passa a ser um desenvolvimento, de forma planejada, que permitisse a montagem de infra-estrutura para o recebimento da produção diversificada, como armazéns e silos, mas, sobretudo, que atingisse um crescimento vertical através da agroindustrialização. As cooperativas agropecuárias caminhavam para a competição num mercado bem mais complexo do que a simples comercialização de produtos agrícolas: o mercado agroindustrial. Para que atingissem a agroindustrialização, as cooperativas atuaram ativamente no processo de modernização agrícola, que incluía a diversificação e substituição de culturas, a utilização, de forma cada vez mais ampliada, de insumos industriais modernos, inovações tecnológicas e máquinas.

Beneficiadas com créditos oficiais, as cooperativas funcionavam como instrumento de difusão das novas técnicas de produção, desse modo servindo aos interesses do Estado de promover a modernização na agricultura.

Intermediando a compra de insumos industriais, repassando créditos e garantindo o fluxo normal da pro- dução (FONSECA e COSTA, 1995, p. 365), as cooperativas consolidam sua posição na comercialização de produtos agrícolas, congregando interesses dos grandes produtores, do Estado e das próprias agroindústrias (IPARDES, 1986, p. 174).

Resta dizer que apesar da integração das cooperativas agropecuárias a nível nacional também ter ocorrido, através de um intenso movimento cooperativista levado a cabo nas décadas de 70 e 80, com um intercâmbio cada vez maior e mais estreito entre as cooperativas brasileiras, continuam a persistir as marcantes diferenças regionais no setor econômico cooperativado (VAN KAICK, 1986, p.9). No caso do Paraná, a diferença essencial está no nível de desenvolvimento das cooperativas. Enquanto algumas despontam no cenário econômico por sua força e pujança, outras caminham com maior dificuldade.

\section{AS AGROINDÚSTRIAS COOPERATIVAS NA ECONO- MIA PARANAENSE}

A economia paranaense teve na agroindústria seu mais importante eixo de industrialização. Desde os primórdios de sua colonização, a agroindústria se fez presente, inicialmente com o processamento do mate, da madeira e mais tarde do café. Mas essa antiga agroindústria, na realidade, tratava-se de um primeiro beneficiamento de produtos primários, de forma rústica, não tendo vínculo com o setor agroindustrial moderno e o CAl.

Entretanto, essas agroindústrias persistiram, restringindo-se às etapas iniciais do processamento, fornecendo matérias-primas (elaboradas ou semi-elaboradas) para indústrias do Estado de São Paulo. E representaram importante participação na economia estadual.

"Em 1970, a agroindústria representava aproximadamente $75 \%$ do valor da produção da indústria paranaense, $45 \%$ do pessoal ocupado e $65 \%$ do valor da transformação industrial". (ASSUMPÇÃO, GALINA e CONSONI, 1991, p. 21). Mais adiante, durante a década de 70, a agroindústria firma-se como expressão da industrialização paranaense. A abundância de matéria-prima faz com que o Norte do Estado seja vantajoso para localização de unidades processadoras. "A partir de 1976 a indústria passa a superar a agricultura na geração de renda, destacando-se como principal gênero a agroindústria alimentar, composta basicamente pelos ramos: produtos alimentares e produção de óleos vege-

\footnotetext{
${ }^{3}$ Deve-se salientar que a Cooperativa Agropecuária Mouraoense - COAMO - ainda na década de 70, passou a ser responsável por uma área que ultrapassa a delimitação original do projeto NORCOOP. Esse espaço dentro do projeto SULCOOP, que englobava na época os municípios de Palmas, Bituruna, Mangueirinha e General Carneiro, passou, assim, a incorporar o NORCOOP.
} 
tais em bruto". (ASSUMPÇÃO, GALINA e CONSONI, 1990, p.135). A participação das cooperativas no setor agroindustrial cresce significativamente; estas atuam para completar a verticalização do processo produtivo fornecendo os insumos, agindo em todas as etapas da produção agrícola com assistência técnica, processando e industrializando os produtos. Um típico exemplo é o óleo de soja refinado, para o consumo final.

Foi justamente durante a década de setenta que a indústria supera a participação da agricultura na geração de renda interna no Estado (LEÃO, 1989, p. 28), sendo que se tratava de agroindústrias.

A explicação pode ser parcialmente encontrada no caráter moderno e dinâmico da agricultura estadual, uma vez que a agroindústria constitui a principal vertente do crescimento industrial. Entretanto, a indústria também se diversifica, instalando-se gêneros e grupos industriais novos. Atuaram aí diversos fatores, como as condições locacionais do Paraná, a definição de uma política de desenvolvimento, centrado no BADEP, a instalação de uma infra-estrutura de transporte e energia elétrica adequada ao investimento industrial e o fato de a economia brasileira atravessar um período expansivo, com retomada dos investimentos privados. (LEÃO, 1989, p. 28).

Em meados dos anos 70, o eixo Maringá-Londrina já é a maior área agroindustrial do Paraná, como se pode ver na afirmação do Instituto Paranaense de Desenvolvimento Econômico e Social (IPARDES) em levantamento para Estudo de Integração de Pólos agroindustriais do Paraná: "O eixo Maringá-Londrina, incluindo apenas os municípios ao longo do trecho rodoviário e ferroviário, participa com 19\% da indústria de transformação do Estado e com aproximadamente 22\% da agroindústria, o que a qualifica como a principal área agroindustrial do Paraná". (IPARDES, 1974, p. 34).

Boa parcela da expansão das agroindústrias na década de 70 tem relação com a própria expansão cooperativista no setor. Grandes investimentos, empreendimentos de cooperativas, impulsionaram a atividade agroindustrial. Ao mesmo tempo em que as mesmas iniciavam seus esforços para participar da cadeia completa de produção, elas conquistavam seu espaço nesse mercado extremamente competitivo, dominado por grandes empresas (OCEPAR, 1990, p.8). Os financiamentos estatais tiveram, nesse sentido, papel de fundamental importância. Desse modo, as agroindústrias cooperativas se multiplicaram durante os anos 70 e 80 , período mais dinâmico para as mesmas.

Por outro lado, a agricultura perde seu dinamismo - enquanto força isolada - no agronegócio conforme se esgotam as áreas para expansão do cultivo. E isso se deve em parte ao surto de agroindustrialização liderado pelas cooperativas agropecuárias, sobretudo, nos anos 80 (LAURENTI, 1998, p.473), que acabou por concentrar o valor adicionado do agronegócio, em contraposição ao decréscimo gradativo da contribuição da atividade agropecuária propriamente dita.

Do lado dos financiamentos dos investimentos agroindustriais, o crédito rural havia beneficiado enormemente o D1 entre 1970 e 1980 (pois ampliou a demanda de máquinas e insumos devido à própria modernização) consolidando a agricultura como mercado às indústrias a montante, do lado das agroindústrias "(...) as políticas tenderam a ter caráter mais específico, ligadas a certas atividades, produtos e regiões" (GRAZIANO DA SILVA, 1996, p. 39). Estas condições já estavam colocadas desde a instituição do Sistema Nacional de Crédito Rural em 1965, que permitiu que se consolidasse o chamado padrão integrado de crescimento agrícola sustentado até o final da década de 70 (PASSOS, 1990, p.5).

Por outro lado, as cooperativas encontraram no Estado um forte aliado. As políticas institucionais baseadas em incentivos fiscais e créditos específicos para financiamentos das empresas cooperativas nas suas iniciativas de investir no setor agroindustrial - aliadas a políticas de financiamento da produção e de preços mínimos - demonstram a preocupação estratégica das ações estatais com relação às cooperativas agropecuárias (LOURENÇO, 1992, p.131). A união de interesses entre cooperativas e Estado possibilitou uma enorme expansão das cooperativas, principalmente em participação na agroindústria de óleos vegetais.

Acerca dessa expansão, é importante ressaltar que esta se deu com intensa concentração, conferindo às cooperativas amplas possibilidades de inversão de capitais em segmentos industriais articulados com a agricultura, principalmente na verticalização da produção em direção às indústrias de processamento e distribuição de matérias-primas. Isto significa que a incorporação do capital da própria agricultura mediante a migração de recursos, oriundos do patamar de acumulação já alcançados pelas cooperativas, para a agroindustrialização contribui para a transformação da agricultura paranaense em direção a produtos de maior valor adicionado, resultando em mudanças significativas na estrutura produtiva do Estado. (PEREIRA, 1995, p. 36).

Como lembra Leão (1989, p. 45), é evidente que, a partir de 1979, com a perda em boa parte dos financiamentos subsidiados, o crescimento das cooperativas passa a depender crescentemente da sua capacidade de autocapitalização. E a partir daí, se manifesta mais intensamente uma contradição própria a esse tipo de instituição, que fica presa à necessidade de acumular e, ao mesmo tempo, a uma base de pequeno e médios produ- 
tores cujos interesses não são, em curto prazo, os mesmos da cooperativa.

As dificuldades enfrentadas pelas cooperativas poderiam ser ainda maiores, caso não houvesse a ajuda institucional. Como afirma Kosloviski (1986, p. 28):

Por isso, torna-se imprescindível que os dirigentes das cooperativas e associados se conscientizem de que os tempos mudaram, os financiamentos a custo zero para aquisição de insumos ou para investimento e capitalização a juros subsidiados já não existem, havendo necessidade de um redimensionamento de toda a prática adotada neste setor.

Em relação aos produtores agropecuários não cooperados, muitos destes integraram-se às agroindústrias via contratos. "Estas integrações apresentam níveis importantes de controle industrial sobre a produção agrícola tanto na determinação dos aspectos tecnológicos da atividade, tendo em vista os parâmetros específicos de qualidade, como no controle da quantidade e fixação dos preços". (BRANDENBURG e FERREIRA, 1995, p. 66). Ao mesmo tempo em que essa relação contratual "moderniza" o produtor, enquanto empresário rural especializado, cria a dependência de um em relação ao outro. $O$ agricultor submete-se às condições impostas pela agroindústria. Como afirma Lauschner (1984, p. 78): "O empresário rural já não será orientado pelas grandes oscilações de preços, mas pelo planejamento racional da agroindústria. Quando o agricultor resiste ao processo de integração na agroindústria, esta, por vezes, o substitui e realiza mesmo toda ou parte da produção rural".

No caso da agroindústria cooperativa, esta oferece algumas vantagens ao agricultor cooperado, como a possibilidade de participação nos resultados, assistência constante ao produtor e facilidades de créditos e compra de insumos. Assim, as cooperativas prestam serviços relevantes:

Estabelecem diretrizes para a produção dos associados numa perspectiva mercadológica, vendem em comum os produtos "in natura" ou elaborados, dando maior poder de barganha aos seus associados. Outra função relevante é o fornecimento de bens de consumo e de bens duráveis, reduzindo através de compra comum e de maior volume o processo de intermediação, conseqüentemente os preços finais a serem pagos pelos cooperados. (CARVALHO; BRITO; PEREIRA, 1993, p.47).
No Paraná, as cooperativas que se industrializaram

\begin{abstract}
... apresentam uma maior estabilidade e estão conseguindo pagar seus investimentos e ainda dar um preço maior pela produção de seus associados podendo-se afirmar que aquelas que permaneceram na fase primária da produção sempre estarão mais susceptíveis às oscilações e intranqüilidade do setor agrícola. (OCEPAR, 1990, p. 16).
\end{abstract}

As cooperativas passam assim a raciocinar como agroindústrias. "Participam da divisão territorial, evitando competir com os gigantes do ramo. Entretanto podem constituir-se num instrumento que ajude os agricultores a obterem melhor barganha com a agroindústria". (ALVES, 1988, p. 15).

Até o início dos anos 90 o setor secundário paranaense ainda estava concentrado na agroindústria. "Entretanto, isto não significa que a indústria esteja subordinada à agricultura e ao seu dinamismo, ao contrário, é a indústria que atrela a si a produção agrícola e esta passa a adotar tecnologias de acordo com os interesses do capital industrial". (TRINTIN, 1993, p. 89).

Como um dos fatores condicionantes para o sucesso da agroindústria em determinada região, relaciona-se com a potencialidade da produção de matéria-prima para atender a demanda (VEIGA, 1980, p. 317), o interior do Estado do Paraná ainda apresenta uma forte "vocação" para as atividades agroindustriais.

\section{DIVERSIFICAÇÃO E VERTICALIZAÇÃO DAS COOPE- RATIVAS NO SETOR AGROALIMENTAR}

Na medida em que as cooperativas tornam-se transformadoras de matérias-primas, segundo Medeiros (1997, p. 4), passam a " (...) internalizar em suas atividades econômicas, o processo de integração vertical, notadamente a partir dos anos $70 \mathrm{com}$ a implementação da política agrícola".

No Norte paranaense, a soja constituiu-se em importante setor responsável pela agroindustrialização. E atualmente o chamado complexo soja tem papel marcante nas exportações paranaenses (WOSCH, 1996, p.15), representando o setor de maior participação no Agribusiness estadual.

A partir do final da década de 70, ganham destaque a moagem dos grãos e a produção de óleo ${ }^{4}$, sendo que a COCAMAR (Cooperativa dos Cafeicultores e Agropecuaristas de Maringá) instala sua indústria em 1979,

4 Belik (1994, p. 13) ressalta as transformações aceleradas do setor de óleos vegetais. Se na década de 70 esse era um mero subproduto do farelo e torta de soja, passa a ser base de consumo no Brasil nos anos de 1980. 
FAJARDO, S. O novo padrão de desenvolvimento agroindustrial...

entrando num mercado oligopólico dominado por grandes empresas não cooperativas como Sanbra, Anderson Clayton, Cargill, Braswey e outras, que já trabalhavam com grãos, localizadas nos pólos agroindustriais de Londrina, Maringá e Apucarana. Outras cooperativas passam a atuar na cadeia de oleaginosas como a COAMO - Cooperativa Agropecuária Mouraoense - e a COROL - Cooperativa Agropecuária Rolândia.

A eficiência da inserção da empresa no comércio de matérias-primas e de produtos finais é um elemento fundamental para a permanência no mercado ou mesmo liderança do mesmo cuja estrutura é muito próxima de um oligopólio.
Essas características do setor agroalimentar indicam que suas perspectivas, como as da indústria em geral, estão ligadas ao comportamento da grande empresa, não tendo sentido econômico o apoio às pequenas firmas do setor como elemento estratégico de uma política para o seu desenvolvimento. As mesmas características destacam ainda as cooperativas como um segmento empresarial com grande potencial de expansão na agroindústria, surgindo como um dos raros grupos industriais de origem local a investir significativamente no setor nos anos setenta, a partir de sua sólida participação na comercialização de produtos agrícolas. (LEÃO, 1989, p. 64).

TABELA 1 - TAXAS QÜINQÜENAIS DE CRESCIMENTO NO NÚMERO DE ESTABELECIMENTOS AGROINDUSTRIAIS E VALOR AGREGADO NA AGROINDÚSTRIA E INDÚSTRIA DE TRANSFORMAÇÃO DO PARANÁ

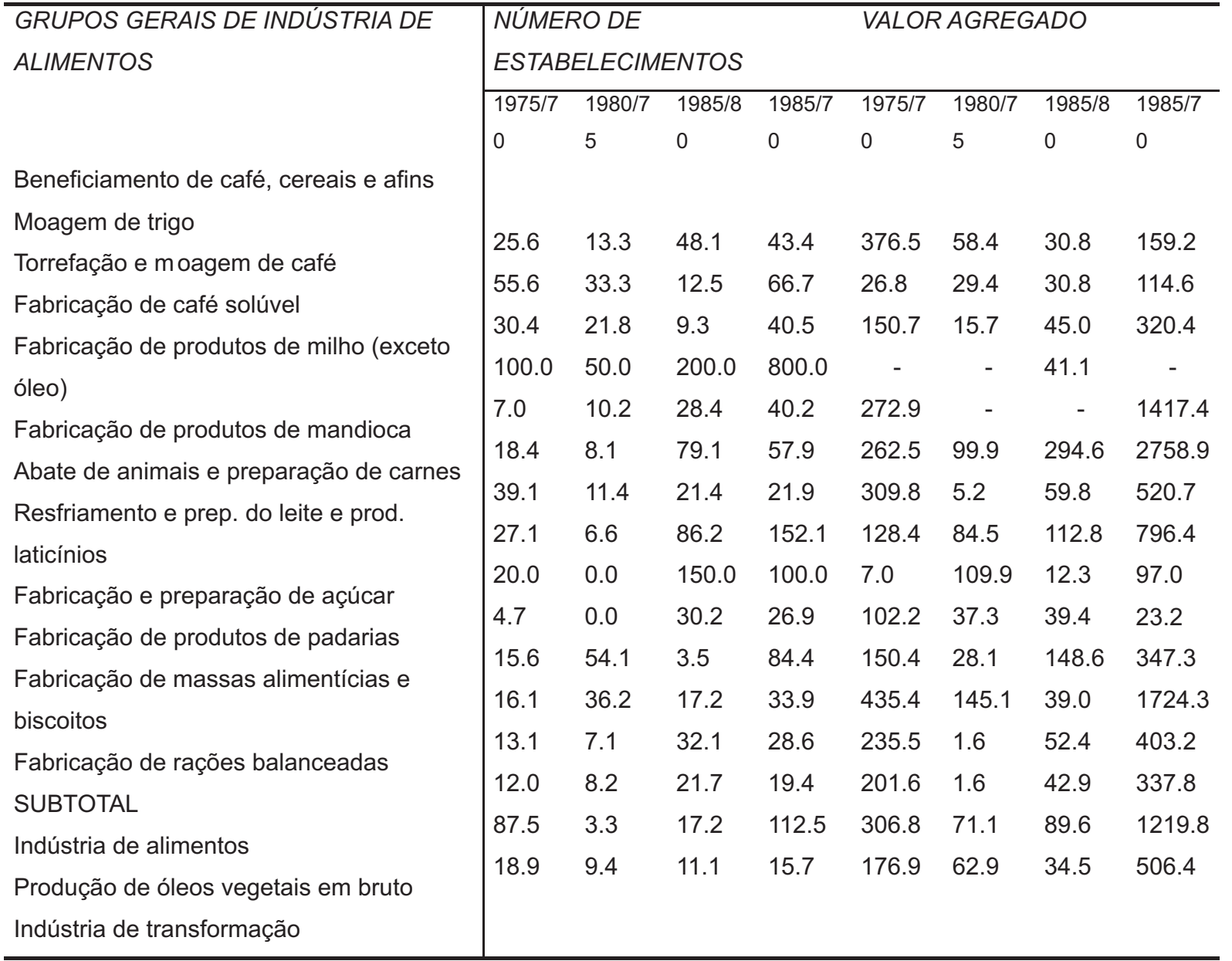

FONTE: IBGE - CENSO INDUSTRIAL DO PARANÁ; 1970, 1975, 1980 E 1985.

ORGANIZAÇ̃̃O: PEREIRA, 1995, p. 29.

NOTAS: (1) Dado não publicado para 1970 e 1975; (2) A produção de óleos vegetais em bruto aparece no gênero química dos censos de 1970 , 1975 e 1980, e apenas no censo de 1985 ocorre uma transferência desta atividade para o Gênero Produtos Alimentares. Assim, para não distorcer os dados, considerou-se esta atividade isolada em todos os anos, o que significou, subtrair os seus valores do gênero Produtos Alimentares no Censo de 1985:

(3) Os dados em Cruzeiro foram corrigidos de acordo com o IGP-DI da FGV (jan. 1970=100). 
Um outro setor que ganha impulso no início da década de 80 é o sucro-alcooleiro, que teve enorme expansão em razão do Pro-Álcool (KOHLHEPP, 1991, p. 87), programa que buscava uma alternativa energética diante da crise do petróleo. Assim surgem muitas destilarias de álcool (juntamente com usinas de açúcar, que utilizam a mesma estrutura) com as cooperativas agrícolas também ingressando nessa atividade.

Ainda dentro do setor agroalimentar destacam-se o processamento do café, trigo e laticínios, todos com a participação de cooperativas. Porém, no Norte do Paraná, o chamado complexo soja desempenhou um papel decisivo na formação do CAI. O fato da cadeia produtiva das oleaginosas, especialmente a soja, possuir vínculos específicos com setores industriais a montante, fornecendo desde sementes selecionadas até máquinas produzidas exclusivamente para esse complexo, colaborou em muito para a consolidação do mesmo.

Vale recordar que a diversificação levada a cabo nos anos 80, trouxe um incremento significativo para a geração e a agregação de valor na economia do Norte do Estado. Como exemplo pode-se citar a produção de fios de algodão, de óleos vegetais refinados e de rações balanceadas (como se observa na Tabela 2).

É preciso dizer que as agroindústrias predominantes até então faziam parte de um determinado padrão de desenvolvimento baseado na disponibilidade de matéria-prima que atraía as agroindústrias processadoras. Durante os anos 1980, conforme Assumpção, Galina e Consoni (1990, p. 136-137) verifi- ca-se:

... uma mudança de padrão de desenvolvimento agroindustrial à medida que não é mais apenas a existência de matéria-prima em abundância que estimula e determina a instalação das agroindústrias processadoras. As agroindústrias são projetadas, até mesmo instaladas, e, paralelamente, são realizados projetos para estimular a produção de matéria-prima pelo setor agrícola de forma integrada.

Isto significa dizer que a produção agropecuária é iniciada em virtude das possibilidades de ganhos com a agroindústria. Como exemplo, os autores mencionados utilizam o caso da sericicultura incentivada pela COCAMAR quando iniciava a implantação de uma fiação de seda.

O caso da cana-de-açúcar é semelhante, quando essa cultura é cultivada para a produção de álcool (devido aos estímulos do Pro-Álcool) e não apenas em função da produção de açúcar. Por outro lado, outras atividades também têm expansão nesse processo de diversificação como a avicultura: conforme se percebe num estudo do IPARDES (1985, p.11):

Entre 1975-83, os grupos Abate de Animais e Fabricação de Rações Balanceadas, apresentaram destacado desenvolvimento chegando a representar em 1983 quase $20 \%$ do valor adicionado da agroindústria agroalimentar [...] sendo que a avicultura foi um dos principais responsáveis pelo desempenho de abate de animais, tendo em vista o significativo desenvolvi-

GRÁFICO 1 - PARTICIPAÇÃO DOS ESTABELECIMENTOS, SEGUNDO TAMANHO, NAS SAÍDAS TOTAIS, NO PARANÁ - 1975 - 1980 - 1983.

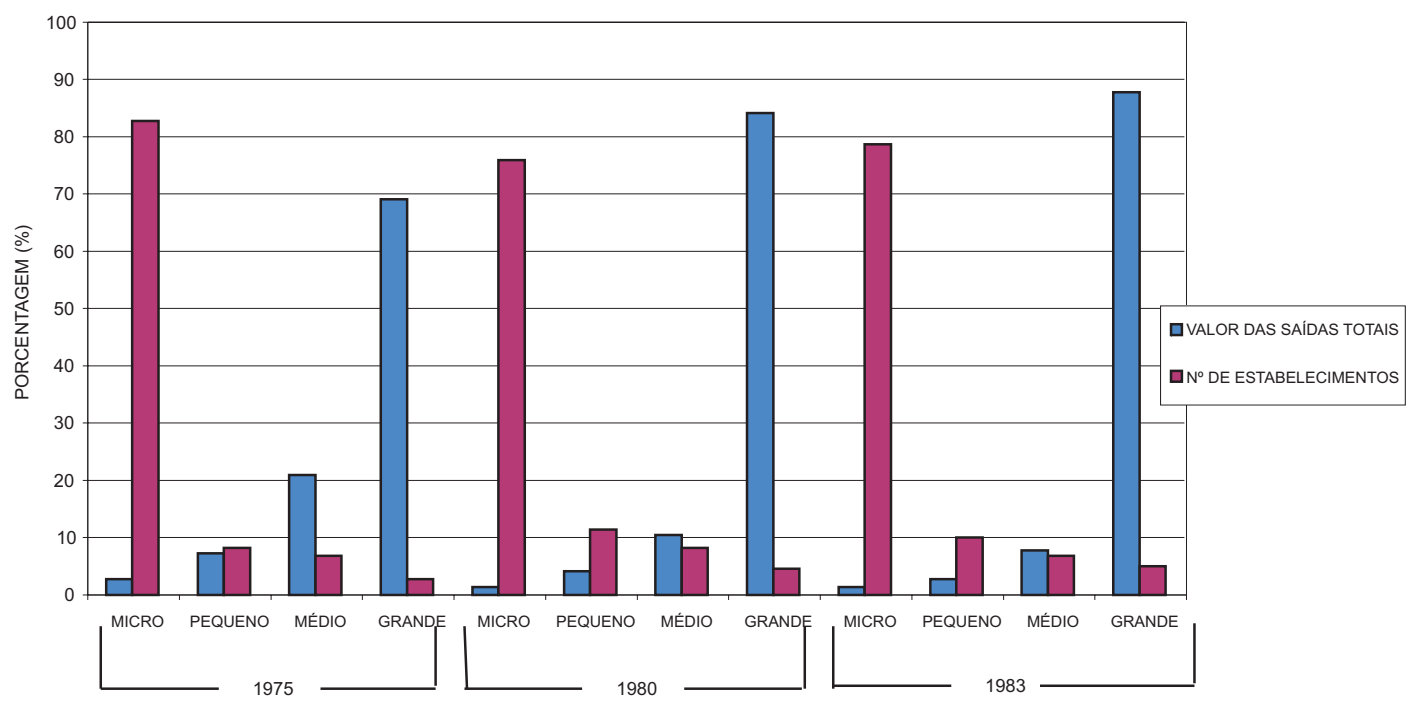

FONTE: IPARDES, 1985, p. 20. 
FAJARDO, S. O novo padrão de desenvolvimento agroindustrial...

TABELA 2 - PARTICIPAÇÃO PERCENTUAL DOS ESTABELECIMENTOS AGROINDUSTRIAIS POR TAMANHO*, NAS SAÍDAS TOTAIS DA INDÚSTRIA AGROALIMENTAR NO PARANÁ, SEGUNDO DIVERSOS GRUPOS - 1975, 1980 E 1983.

\begin{tabular}{|c|c|c|c|c|c|c|c|c|c|c|c|c|}
\hline \multirow[t]{2}{*}{ GRUPO } & \multicolumn{4}{|c|}{1975} & \multicolumn{4}{|c|}{1980} & \multicolumn{4}{|c|}{1983} \\
\hline & $\begin{array}{l}\text { MICRO } \\
\end{array}$ & PEQUENO & MEDDIO & GRANDE & MICRO & PEQUENO & MEDDIO & GRANDE & MICRO & PEQUENO & MÉDIO & GRANDE \\
\hline Benefic. café e cereais & 3.4 & 12.4 & 34.5 & 49.7 & 3.4 & 9.8 & 22.5 & 64.3 & 3.0 & 7.2 & 18.7 & 71.1 \\
\hline Moagem de trigo & 2.7 & 11.7 & 37.3 & 48.3 & 1.4 & 3.5 & 24.1 & 71.0 & 0.7 & 1.7 & 23.8 & 73.8 \\
\hline Torref. de café & 4.6 & 19.2 & 48.9 & 27.3 & 2.7 & 11.4 & 26.0 & 59.9 & 2.1 & 5.7 & 35.5 & 56.7 \\
\hline Fab. de Prod. de milho & 11.0 & 15.2 & 51.5 & 22.3 & 5.9 & 5.0 & 31.9 & 57.2 & 2.7 & 2.8 & 12.8 & 81.7 \\
\hline Fab. de café e mate solúvel & 0.0 & 0.0 & 0.0 & 00 & 100.0 & 0.0 & 0.5 & 0.0 & 99.5 & 0.0 & 0.1 & 0.0 \\
\hline Abate de animais & 2.3 & 1.4 & 8.7 & 87.6 & 0.6 & 2.1 & 7.7 & 89.6 & 0.4 & 1.5 & 5.6 & 92.5 \\
\hline Fab. de rações balanceadas & 1.5 & 6.5 & 8.7 & 83.3 & 1.1 & 3.0 & 13.2 & 82.7 & 0.6 & 3.0 & 5.5 & 90.9 \\
\hline Resf. do leite & 14.3 & 51.6 & 34.1 & 0.0 & 1.4 & 30.7 & 67.9 & 0.0 & 0.9 & 27.3 & 71.8 & 0.0 \\
\hline Prep. do leite & 30.7 & 69.3 & 0.0 & 0.0 & 1.9 & 4.6 & 26.5 & 67.0 & 1.8 & 26.6 & 15.0 & 56.5 \\
\hline Fab. de prod. de laticínio & 1.9 & 11.4 & 32.0 & 54.7 & 1.1 & 5.2 & 18.3 & 75.4 & 2.2 & 7.0 & 9.9 & 80.9 \\
\hline Fab. de açúcar & 0.4 & 0.0 & 0.0 & 99.6 & 0.0 & 0.2 & 0.6 & 96.2 & 0.0 & 0.0 & 0.0 & 100.0 \\
\hline Fab. de massas & 15.6 & 8.8 & 75.6 & 0.0 & 3.2 & 9.2 & 8.4 & 79.2 & 2.7 & 10.2 & 29.0 & 58.1 \\
\hline Fab. de biscoitos & 3.3 & 3.5 & 20.7 & 72.5 & 2.3 & 1.7 & 0.0 & 96.0 & 3.0 & 0.0 & 10.2 & 86.8 \\
\hline Ref. e prep. de óleos vegetais & 0.3 & 0.1 & 2.5 & 97.1 & 0.0 & 0.0 & 0.4 & 99.6 & 0.0 & 0.1 & 0.1 & 99.8 \\
\hline Prod. de óleo vegetal em bruto & 0.0 & 0.3 & 5.7 & 94.0 & 0.0 & 0.1 & 1.4 & 98.5 & 0.0 & 0.0 & 0.0 & 100.0 \\
\hline TOTAL & 2.8 & 7.3 & 21.0 & 68.9 & 1.5 & 4.0 & 10.5 & 84.0 & 1.3 & 2.9 & 7.9 & 87.9 \\
\hline Estabelecimento (\%) & 82.6 & 8.1 & 6.7 & 2.6 & 75.9 & 11.5 & 8.0 & 4.6 & 78.5 & 9.8 & 6.7 & 5.0 \\
\hline
\end{tabular}

FONTE: SEFI/ASSESSORIA ECONÔMICA.

* Critério do Banco do Brasil: Microestabelecimento com faturamento anual até 5.000 MRV (maior valor de referência); Pequeno - até 20.000 e 85.000 MRV; Grande - acima de 85.000 MRV.

ORGANIZAÇÃO: IPARDES, 1985, p. 20.

mento desse segmento industrial motivado pela implantação de empresas modernas operando com sistemas integrados bem como pelo estímulo à exportação.

Apesar da existência em grande número de estabelecimentos de porte micro (com relação ao faturamento) no setor agroalimentar, nota-se, observando os dados de participação nesse setor, que há uma concentração no lado dos grandes estabelecimentos. (Gráfico 1 e Tabela 3). A expansão das cooperativas em relação à participação na indústria agroalimentar, tanto em ramos tradicionais como o beneficiamento de café, cereais, produtos afins e laticínios, como no abate de animais e produção de óleos vegetais, colocou os estabelecimentos cooperativados, em 1983, entre os cinco que geravam mais valor adicionado (IPARDES, 1985, p. 21).

Com respeito à localização da agroindústria, quase não houve concentração no Estado do Paraná. Pois um dos fatores determinantes para a localização da mesma está, de modo geral, relacionado à proximidade de centros produtores de matéria-prima. Desse modo, encontra-se distribuída pelo interior do Estado.
No entanto, algumas regiões respondem pela maior parte do valor agregado pela indústria agroalimentar. Como se pode ver na Figura 2, em 1983 as microrregiões homogêneas de Curitiba, Ponta Grossa, Londrina, Maringá e Extremo Oeste "(...) são responsáveis por 77\% do valor adicionado gerado pela indústria agroalimentar". (IPARDES, 1985, p. 31), sendo que o conjunto das microrregiões do norteparanaense ultrapassava 45\% desse valor. Tal fato não deixa de revelar uma dispersão concentradora.

Uma outra questão diz respeito à dinâmica interna do agronegócio paranaense. O setor agroalimentar tende a comprar a maioria dos insumos e matérias-primas de fornecedores locais (IPARDES, 1994, p. 47-48), o que demonstra seu vínculo com a economia estadual.

As Tabelas 3 e 4 mostram a participação do cooperativismo nos setores agroindustriais em dois momentos: em 1983, dentro do conjunto dos maiores estabelecimentos agroindustriais, segundo valor adicionado; e num segundo momento, no final da década de 90 , a participação das cooperativas segundo capacidade instalada demonstram a força e a presença cooperativista na produção agroindustrial. 
FIGURA 2 -PARANÁ - ESQUEMA DA DISTRIBUIÇÃO ESPACIAL DO VALOR ADICIONADO TOTAL DA INDÚSTRIA AGROALIMENTAR POR MICRORREGIÃO EM 1983

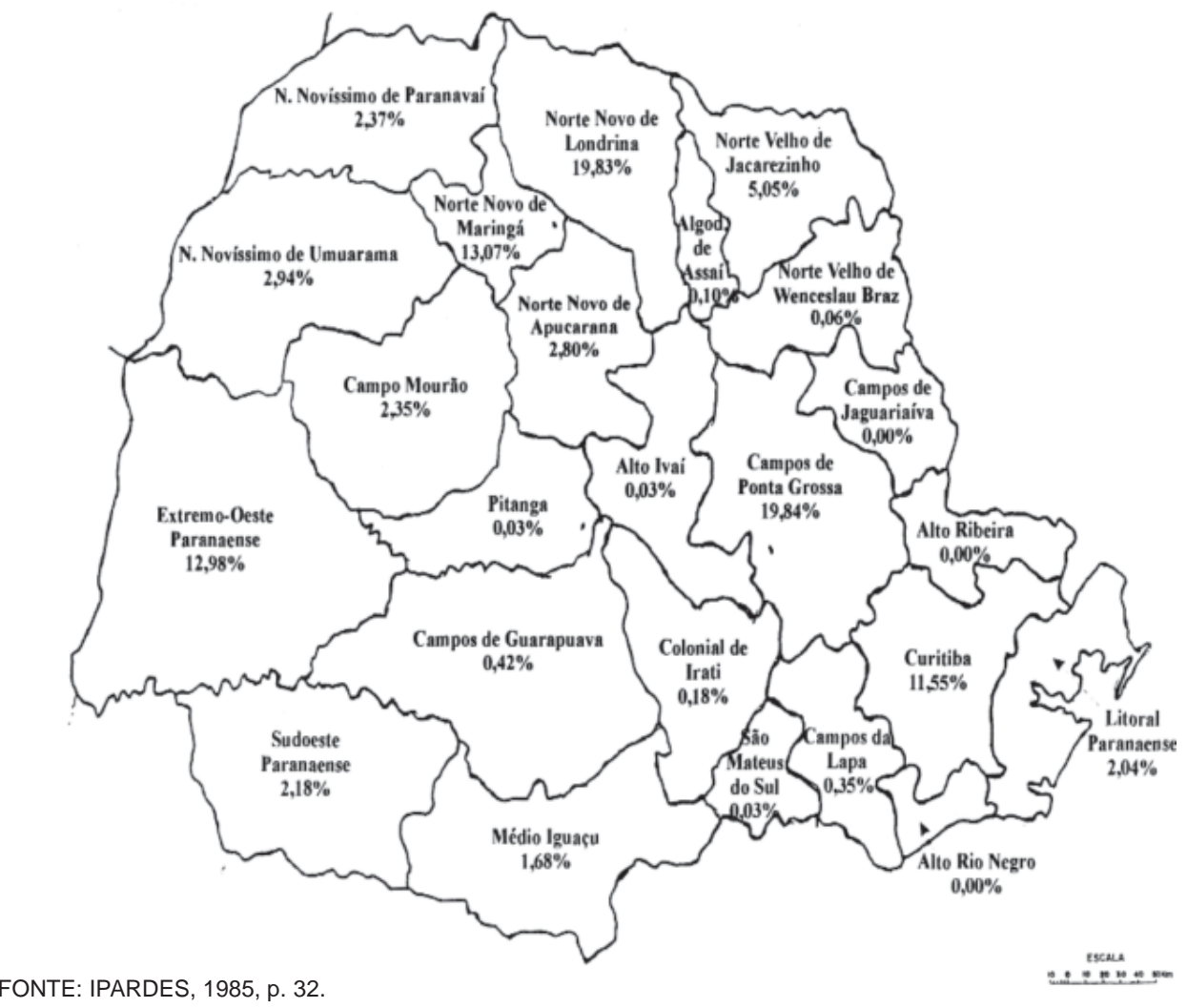

Percebe-se (a partir dos dados das tabelas 3 e 4), que as cooperativas mantiveram sua participação considerável em alguns setores agroindustriais como o de laticínios e de beneficiamento de café, e expandiram em outros. Mas continua baixa a participação das cooperativas em setores agroindustriais das cadeias do milho, por exemplo. Merecem destaque as agroindústrias de rações e fiações de algodão e seda, cuja participação cooperativista deu um salto na década de 80 juntamente com as indústrias de álcool.

\section{CONSIDERAÇÕES SOBRE AS RECENTES ALTERA- ÇÕES NO SETOR AGROINDUSTRIAL DO PARANÁ E A ATUAÇÃO DAS COOPERATIVAS}

O cenário da última década do século $X X$ apresenta um forte impulso no setor agroindustrial motivado pelas transformações nos padrões de consumo e hábito da população. As novas exigências em termos de qualidade dos produtos de origem agropecuária e agroindustrial impõem desafios tecnológicos e estratégias mercadológicas e organizacionais, para as empresas do segmento agroindustrial e para a própria atividade agropecuária.
Mudanças nas formas de comercialização dos produtos, como embalagens e conservação, refletem a competitividade pela busca do mercado consumidor. Atualmente, as condições postas exigem um pensamento empresarial dinâmico com a criatividade, racionalidade, difusão de tecnologias e também o uso do marketing pelas agroindústrias processadoras. Assim, cada vez mais, os padrões internacionais devem orientar todo o processo de produção e comercialização dos produtos de origem agropecuária. Fato que exige custos altos de investimentos.

Uma outra questão se refere à biotecnologia cada vez mais presente no setor agropecuário e agroindustrial. Lemos (1995, p. 63) aponta a genética como base do sistema agroindustrial, ou seja, é o ponto comum do conjunto das atividades produtivas dos grupos componentes. Cada vez mais as modificações no agribusiness impulsionadas pelos avanços na informática e biotecnologia.

Nesse quadro que caracteriza o período de intensa e acirrada competição pelos mercados nacional e internacional, da chamada globalização da economia, as cooperativas enquanto também agroindústrias são obrigadas a mudar suas formas de organização, comercialização e relação com os demais componen- 
FAJARDO, S. O novo padrão de desenvolvimento agroindustrial...

TABELA3 - PARTICIPAÇÃO DOS MAIORES ESTABELECIMENTOS AGROINDUSTRIAIS DO ESTADO DO PARANÁ NO VALOR ADICIONADO

\begin{tabular}{|c|c|c|c|c|}
\hline GRUPO AGROINDUSTRIAL & CLASSIF & NATUREZA & $\%$ & ACUMULADO \\
\hline \multirow[t]{5}{*}{ Benef. de café e prod. afins } & 1 & COOP. & 10.62 & 10.62 \\
\hline & 2 & NÃO-COOP. & 7.61 & 18.23 \\
\hline & 3 & COOP. & 4.97 & 23.20 \\
\hline & 4 & COOP. & 3.87 & 27.07 \\
\hline & 5 & COOP. & 2.69 & 29.76 \\
\hline \multirow[t]{5}{*}{ Fabricação e Produção do milho } & 1 & NÃO-COOP. & 40.27 & 40.27 \\
\hline & 2 & NÂO-COOP & 22.73 & 63.00 \\
\hline & 3 & NÄO-COOP. & 17.19 & 80.19 \\
\hline & 4 & NÃO-COOP. & 8.39 & 88.58 \\
\hline & 5 & NÃO-COOP. & 6.09 & 94.67 \\
\hline \multirow[t]{5}{*}{ Fabricação de produtos do Laticínio } & 1 & COOP. & 61.71 & 61.71 \\
\hline & 2 & COOP. & 9.32 & 71.03 \\
\hline & 3 & COOP. & 6.26 & 77.29 \\
\hline & 4 & COOP. & 4.08 & 8.37 \\
\hline & 5 & COOP. & 2.70 & 84.07 \\
\hline \multirow[t]{3}{*}{ Fabricação de café e mate solúvel ${ }^{*}$} & 1 & NÃO COOP. & 70.22 & 70.22 \\
\hline & 2 & NÃO-COOP. & 29.57 & 99.79 \\
\hline & 3 & NÃO-COOP. & 0.19 & 99.98 \\
\hline \multirow[t]{5}{*}{ Fabricação de açúcar } & 1 & NÃO-COOP. & 60.24 & 60.24 \\
\hline & 2 & NÃO-COOP. & 18.82 & 79.06 \\
\hline & 3 & COOP. & 14.97 & 94.03 \\
\hline & 4 & NÃO-COOP. & 5.95 & 99.98 \\
\hline & 5 & NÃO-COOP. & 0.00 & - \\
\hline \multirow[t]{5}{*}{ Abate de animais } & 1 & NÃO-COOP. & 58.05 & 58.05 \\
\hline & 2 & NÃO-COOP. & 7.61 & 65.66 \\
\hline & 3 & NÃO-COOP. & 3.43 & 69.09 \\
\hline & 4 & NÃO-COOP. & 2.54 & 71.63 \\
\hline & 5 & COOP. & 2.44 & 74.07 \\
\hline \multirow[t]{5}{*}{ Produção de óleos em bruto } & 1 & NÃO-COOP. & 51.29 & 51.29 \\
\hline & 2 & COOP. & 13.95 & 65.24 \\
\hline & 3 & NÃO-COOP. & 11.34 & 76.58 \\
\hline & 4 & COOP. & 8.66 & 85.24 \\
\hline & 5 & NÃO-COOP. & 4.41 & 89.65 \\
\hline \multirow[t]{5}{*}{ Fabricação de rações balanceadas } & 1 & NÂO-COOP. & 25.80 & 25.80 \\
\hline & 2 & NÂO-COOP. & 19.13 & 44.93 \\
\hline & 3 & NÃO-COOP. & 14.07 & 59.00 \\
\hline & 4 & NÃO-COOP. & 5.00 & 64.00 \\
\hline & 5 & NÃO-COOP. & 4.71 & 68.71 \\
\hline \multirow[t]{5}{*}{ Refinação e prep. de óleos vegetais } & 1 & NÃO-COOP. & 25.96 & 25.96 \\
\hline & 2 & NÃO-COOP. & 20.30 & 46.26 \\
\hline & 3 & NÂO-COOP. & 12.04 & 58.83 \\
\hline & 4 & NÃO-COOP. & 10.99 & 69.29 \\
\hline & 5 & NÃO-COOP. & 10.33 & 79.62 \\
\hline
\end{tabular}

FONTE: IPARDES, 1985, p. 22.

(*) O grupo Fabricação de café e mate solúvel não contava na época com cinco grandes estabelecimentos.

tes ${ }^{5}$ do Complexo Agroindustrial, como já fazem grandes empresas do setor. Grandes empresas têm suas definições e volume de investimentos dados mais pelo equacionamento de pontos estratégicos de infra-estrutura, armazenagem e distribuição, viabilizando sua penetração nos grandes centros consumidores para racionalizar sua atuação comercial, do que pela simples localização de plantas industriais. (URBAN, 1990, p. 3). No caso das cooperativas, estas:
... já estão cientes da necessidade de se estruturarem da melhor forma possível para enfrentarem a crescente competitividade do setor. A clareza da importância que assume a atividade agroindustrial para seu processo de acumulação de capital as tem levado a buscar todos os mecanismos possíveis para romper algumas amarras formais e institucionais que limitam sua atuação empresarial, já se aventando a hipótese de formação em sociedade anônima e integração empresarial com cooperativas européias.

${ }^{5}$ Um dos fatores importantes e relevantes na reordenação das atividades agroindustriais nesse fim de século está na logística e localização das agroindústrias. Segundo Martins e Cypriano (1998, p. 959-971) se observados os menores custos de transportes, a melhor localização, por exemplo, das agroindústrias de trigo seria nas proximidades das áreas fronteiriças com a Argentina, pois a maior parte da matéria-prima vem desse país. Já para a cadeia da soja, de acordo com os mesmos autores, a melhor localização agroindustrial é mesmo dispersa em todo o Estado como se encontra atualmente. 
TABELA 4 - SEGMENTOS AGROINDUSTRIAIS NO PARANÁ E PARTICIPAÇÃO DAS COOPERATIVAS - INSTALADOS EM 1998

\begin{tabular}{|c|c|c|}
\hline SEGMENTO & CAPACIDADE TOTAL & PARTICIPAÇÃO DAS \\
\hline AGROINDUSTRIAL & INSTALADA & COOPERATIVAS (\%) \\
\hline RAÇÕES & $9.400 \mathrm{t} / \mathrm{dia}$ & 32 \\
\hline \multicolumn{3}{|l|}{ LEITE } \\
\hline Usina de beneficiamento & 2.500 .000 litros/dia & 86 \\
\hline Derivados Lácteos & $500 \mathrm{t} / \mathrm{dia}$ & 52 \\
\hline Leite em Pó & 150.000 t/dia & 100 \\
\hline Queijos & $120 \mathrm{t} / \mathrm{dia}$ & 75 \\
\hline \multicolumn{3}{|l|}{ CARNES } \\
\hline Suínos & $2.850 \mathrm{cab} . /$ hectare & 25 \\
\hline Aves & $99.800 \mathrm{cab} . / \mathrm{hectare}$ & 25 \\
\hline Bovinos & $1.650 \mathrm{cab} . /$ hectare & 3 \\
\hline \multicolumn{3}{|l|}{ BENEFICIAMENTO } \\
\hline Algodão & 1.200 .000 t/ano & 70 \\
\hline \multicolumn{3}{|l|}{ FIAÇÕES } \\
\hline Algodão & 61.000 t/ano & 55 \\
\hline Seda & $2.420 \mathrm{t} / \mathrm{ano}$ & 28 \\
\hline MALTE & 85.000 t/ano & 100 \\
\hline TRIGO & 1.400 .000 t/ano & 14 \\
\hline MILHO & 245.161 & 2 \\
\hline \multicolumn{3}{|l|}{ MANDIOCA } \\
\hline Farinha & 250.000 t/ano & 5 \\
\hline Fécula & 138.000 t/ano & 33 \\
\hline \multicolumn{3}{|l|}{ OLEAGINOSAS } \\
\hline Esmag. de soja & $33.240 \mathrm{t} / \mathrm{dia}$ & 22 \\
\hline Esmag. de caroço de algodão & $1.780 \mathrm{t} / \mathrm{dia}$ & 20 \\
\hline Refino & $2.430 \mathrm{t} / \mathrm{dia}$ & 17 \\
\hline \multicolumn{3}{|l|}{ CANA } \\
\hline Açúcar & $4.000 \mathrm{t} / \mathrm{dia}$ & 9 \\
\hline Álcool & 1.270 .000 m3/ano & 37 \\
\hline ARROZ & $5.060 \mathrm{t} / \mathrm{dia}$ & 5 \\
\hline \multicolumn{3}{|l|}{ CAFÉ } \\
\hline Beneficiamento & 950 t/dia & 60 \\
\hline Torrefação & 220 t/dia & 10 \\
\hline
\end{tabular}

FONTE: OCEPAR, 1999. 
FAJARDO, S. O novo padrão de desenvolvimento agroindustrial...

A união de cooperativas em investimentos comuns também já se coloca como forma de atuação e de fortalecimento no setor. (URBAN, 1990, p. 3).

Nesse sentido, as cooperativas paranaenses programam suas inversões em verticalização e nas etapas de maior agregação de valor ao processo produtivo. Para tal iniciativa alguns fatores colaboram, como afirma Paula (1997, p. 40):

O aumento do consumo, resultante da implementação do plano de estabilização no Brasil, é típico para ilustrar a atratividade a novos investimentos. Soma-se isso o processo de integração regional, como é o caso do Mercosul, com o qual o mercado consumidor final se expande significativamente.

Por outro lado, há uma tendência de investimentos das grandes empresas agroindustriais fora do Estado, deslocando-se para o centro-oeste ou mesmo nordeste do país (LOURENÇO, 1998, p.6). Enquanto que os investimentos no próprio Estado são liderados pelas cooperativas.

A impulsão modernizante da agroindústria, capitaneada pelas iniciativas da estrutura empresarial cooperativista em operação no território estadual, é beneficiada pelo domínio exercido sobre a oferta de matéria-prima, pela expressiva capacidade de industrialização disponível, pela atuação regionalizada facilitando a identificação de oportunidades - e pela sustentação em organizações avançadas (do ponto de vista gerencial e de capitalização), o que permite a alocação mais eficiente de recursos em integração das cadeias. (LOURENÇO, 1998, p. 6).

Essa liderança das cooperativas no agronegócio é percebida, ainda conforme Lourenço (1998, p. 6):

... pelo controle sobre diversas etapas do Complexo Agroindustrial, especialmente nos segmentos de produção de soja, trigo, algodão, leite, cevada e café. Sua estratégia abarca a implantação dos ciclos finais de beneficiamento por meio de ganhos tecnológicos e de escala, facilitados pela alteração radical da postura do segmento nos anos 90 , adotando novo modelo de gestão financeirooperacional, priorizando a terceirização, a utilização em comum de parceiros e alianças estratégicas, entre outros avanços.

Essa estratégia apontada por Lourenço (1998, p. 6) é ilustrada pela ação da COCAMAR, a partir do mo- mento que terceiriza certos segmentos da produção, transforma-se em Sociedade Anônima e estabelece parceria com a COAMO. Da mesma forma pode-se citar a CCLP (Cooperativa Central de Laticínios do Paraná) detentora da marca Batavo, que transferiu 51\% do seu controle acionário para a multinacional Parmalat, e, ainda, a fusão das cooperativas CLAC (Cooperativa de laticínios Curitiba) e Witmarsum. Esses fatos ilustram uma nova postura das cooperativas nos anos $90^{6}$.

Mesmo diante das dificuldades enfrentadas pelas cooperativas agropecuárias, em razão da restrição dos subsídios, via elevação dos juros de mercado (sobretudo iniciada na década de 1980), estas vem conseguindo expandir suas atividades e diversificar a produção. Ao mesmo tempo as cooperativas atuam no estímulo ao aumento da produtividade e à diversificação agropecuária. Vale destacar o exemplo do estímulo ao cultivo da canola pela COCAMAR, voltado à produção de óleos especiais.

A respeito da redução no crédito às cooperativas, o valor dos financiamentos caiu drasticamente. Como se pode observar na afirmação de Suzuki Júnior (1998, p.10):"Segundo o Banco Central, os financiamentos concedidos às cooperativas e aos produtores brasileiros totalizaram R\$19,987 bilhões em 1985, enquanto nos anos de 1995 e 1996 as cifras alcançaram, respectivamente, R\$ 7,771 e R\$ 6,792 bilhões".

Em 1994, na tentativa de recuperação da crise econômica nos anos 80, várias cooperativas paranaenses anunciavam a intenção de investimentos no setor agroindustrial (LOURENÇO, 1994, p.16).

Não obstante aos problemas enfrentados pelas cooperativas, cumpre, enfim, destacar a importância do sistema cooperativista na organização da cadeia agroindustrial, e na constituição do CAI, como afirma Suzuki Júnior (1997, p.9):

O cooperativismo e os sistemas de integração, exercem um papel importante junto às pequenas propriedades, unindo-as às grandes empresas. Essa forma de associação viabiliza não somente a atividade de pequenos produtores, como também proporciona o fornecimento de matérias-primas em grande escala para as indústrias.

Outra vantagem do sistema cooperativista é que as cooperativas representam investimentos locais e estes possuem uma identidade socioespacial. Como ressalta Zeferino (1991, p. 82), os investidores locais detêm menor potencial financeiro individual e até mesmo os interesses

${ }^{6}$ COSTA $(1998$, p. 3) refere-se às novas atitudes empresariais como determinantes para a dinâmica do setor agroindustrial dos próximos anos. 
políticos são centrados, o que faz com que os investimentos fiquem dentro dos limites de sua área de vivência até uma certa escala dimensional, quando então os espaços de produção são ampliados. Por sua vez, o investidor externo, trabalhando com um macro-espaço:

... vê pontos de maior ou menor resposta aos seus objetivos de maximização de lucros, contribuindo para uma maior concentração espacial dos resultados desse esforço investidor, pois o número de pontos com potencial desejável de infraestrutura, mercado consumidor local, potencial de desenvolvimento de tecnologia e mão-de-obra qualificada e comunicações é limitado. (ZEFERINO, 1991, p. 82).

No caso das cooperativas, sua área de atuação constitui também seu espaço de investimentos. Entretanto, devido aos fortes fatores de ordem econômica, típicos do capitalismo, a viabilidade prática da aplicação do cooperativismo em sua forma mais pura, original, é colocada em cheque (ARAÚJO, 1982, p.118). Desse modo, a atuação das cooperativas tende cada vez mais a se distanciar dos românticos ideais teóricos, voltando-se, sobretudo, à busca da eficiência econômica da empresa. Mas esse fato não extingue a figura da cooperativa que continua constituindo um tipo peculiar de empresa. As suas particularidades vão desde a sua própria formação como instituição coletiva até os seus objetivos que substituem os lucros por uma ampliação da renda dos associados.

Assim, as cooperativas representam uma possibilidade dos produtores cooperados de serem participantes nos resultados. Como ressalta Pinho (1977, p. 169): “(...) as vantagens que obtém (principalmente da somatória de recursos financeiros e da redução de custos operacionais) compensam amplamente os direitos que renunciaram (autonomia de decisão, status de produtor autônomo, etc.)".

A eficiência do cooperativismo depende, sobretudo, do processo educativo voltado a esse sistema. Esse tipo de empresa, enquanto organização social, não pode ser produto de imposição, mas de criação (VILELA, 1998, p.306).

O tratamento diferenciado dado pelo Estado é outra característica do sistema cooperativista que o difere das demais empresas. Elas representaram, e ainda representam, aliados estratégicos da ação governamental no campo agropecuário. As cooperativas desempenharam um papel de integração de determinadas categorias de produtor, pequenos, médios e grandes ao processo de modernização (IPARDES, 1985, p.1), prestando um serviço de suma importância ao poder constituído, o Estado.

Atualmente, as principais cooperativas paranaenses apresentam-se como "cooperativas agroindustriais", como ocorre nos casos da COAMO e da COCAMAR. Tal classificação resulta do aspecto nitidamente industrial que passou a orientar as cooperativas no processo de verticalização, caracterizando as mesmas em termos de suas estratégias. O competitivo mercado agroindustrial, marcado por grandes grupos oligopolistas e multinacionais, tem nessas cooperativas um tipo de empresa diferenciado, tanto no que se refere ao tratamento e vantagens que obtém junto a créditos e financiamentos de órgãos públicos, quanto na forma organizacional regionalizada e em atuação conjunta.

Outro fator importante está na fixação territorial dessas empresas em determinadas áreas, que, historicamente, construíram sua estrutura regional, organizando o espaço pela condução da diversificação, como agentes da modernização, e introduzindo atividades agroindustriais nos locais onde atuam.

\section{REFERÊNCIAS}

ALVES, Eliseu. A agroindústria e os agricultores. Brasília: Codevasf - Companhia de Desenvolvimento do Vale do São Francisco, 1988.

ARAÚJO, Silvia M. P. de. Eles, a cooperativa: estudo sobre a ideologia da participação. Curitiba, Projeto, 1982.

ASSUMPÇÃO, Antonio G. de; GALINA, Laudenir A.; CONSONI, Reinaldo. Expansão agroindustrial e transformações agrícolas na região de Maringá. Maringá: Fundação Universidade Estadual de Maringá/Centro de estudos socioeconômicos/Departamento de Economia, 1991.

Mudanças no padrão de desenvolvimento agroindustrial: o caso do Norte do Paraná. Revista de Eco- nomia e Sociologia Rural, Brasília, v. 28, n. 4, p. 236-257, out./dez. 1990

BELIK, Walter. Agroindústria e reestruturação industrial no Brasil: elementos para uma avaliação. Revista Economia, Curitiba, n. 18, p. 121-136. 1994.

CARVALHO, José M.; BRITO, Mozart J.; PEREIRA, Valéria G. O cooperativismo e a dinamização tecnológica e empresarial da agricultura brasileira. Caderno de Administração Rural, Lavras, v. 5, n. 1-2, p. 39-50. 1993.

COSTA, Vera M. H. M. A modernização da agricultura brasileira e a formação da agricultura empresarial em dois momentos: nas décadas de 60 e 70 e nos anos 90. In: ENCON- 
FAJARDO, S. O novo padrão de desenvolvimento agroindustrial...

TRO NACIONAL DE GEOGRAFIAAGRÁRIA, 14., Presidente Prudente, mesas redondas, p. 1-3. dez. 1998. v. 2.

FONSECA, Sandra R.; COSTA, Vera M. H. M. As transformações recentes no setor agroindustrial brasileiro: uma abordagem da atividade cooperativista. Boletim de Geografia Teorética, Rio Claro, v. 25, n. 49-50, p. 363-372. 1995.

GRAZIANO DA SILVA, José. A modernização dolorosa: estrutura agrária, fronteira agrícola e trabalhadores rurais no Brasil. Rio de Janeiro: Zahar, 1982.

IPARDES. Instituto Paranaense de Desenvolvimento Econômico e Social. Agroindústria e cooperativas no Paraná. Curitiba, 1985.

. Caracterização da indústria agroalimentar no Paraná. Curitiba, 1986.

Estudo de integração de pólos agroindustriais do Paraná: primeira fase - levantamentos iniciais. Resumo. Curitiba, 1994.

KOHLHEPP, Gerd. Mudanças estruturais na agropecuária e mobilidade da população rural no norte do Paraná (Brasil). Revista Brasileira de Geografia, Rio de Janeiro, v. 53, n. 2, p. 79-94, abr./jun. 1991.

KOSLOVISKI, João P. Autofiscalização em execução no Paraná. In: Propostas cooperativistas. Curitiba: Ocepar, 1986. p. 31-42.

LAURENTI, Antonio C. A evolução recente da economia paranaense com base no agronegócio como um agregado contábil. In: CONGRESSO BRASILEIRO DE ECONOMIA E SOCIOLOGIA RURAL. O agronegócio brasileiro: desafios e perspectivas, Poços de Caldas, 36. Brasília, SOBER, 1998, v. 1, p. $465-477$.

LAUSCHNER, Roque. Agroindústria cooperativa. In: PINHO, D. B. Tipologia cooperativista - manual de cooperativismo. Brasília: CNPq, 1984. p. 76-94.

LEÃO, Igor Z. C. C. O Paraná nos anos setenta. Curitiba: Ipardes/Concitec, 1989.

LEMOS, Mauro B. Sistema agroindustrial brasileiro: metodologia de identificação dos seus agrupamentos produtivos. Nova Economia, Belo Horizonte, v. 5, n. 2. dez. 1995.

LOURENÇO, Gilmar M. Cenários do agronegócio no Paraná: restrições e oportunidades. Análise Conjuntural, Curitiba, v. 20, n. 7-8, p. 3-9, jul./ago.1998.

Os investimentos das cooperativas paranaenses em verticalização e modernização. Análise conjuntural, v. 16, n. 11-12, p. 16-17, nov./dez. 1994.

LOURENÇO, Luiz. Agricultura e cooperativismo. In: ENCOTRO NACIONAL DE GEOGRAFIA AGRÁRIA, 11., 1992, Maringá. Anais... p. 27-43, out. 1992.

MARTINS, Ricardo S.; CYPRIANO, Luiz A. Estudo da localização da agroindústria no Estado do Paraná. In: CONGRES-
SO BRASILEIRO DE ECONOMIA E SOCIOLOGIA RURAL. O agronegócio brasileiro: desafios e perspectivas, 36., Poços de Caldas. Brasília, SOBER, 1998, v. 1. p. 465-477.

MEDEIROS, Natalino H. O mercado agroindustrial cooperativo norte-paranaense e o novo padrão competitivo da década. Maringá: Universidade Estadual de Maringá, Departamento de Economia, out. 1997. Discussão n. 32.

MORO, Dalton Aureo. Substituição de culturas, modernização agrícola e organização do espaço rural no Norte do Paraná. Rio Claro, 1991. Tese (Doutorado) - Instituto de Geociências, Unesp.

OCEPAR - ORGANIZAÇÃO DAS COOPERATIVAS DO ESTADO DO PARANÁ. Cooperativismo agropecuário paranaense. Curitiba, 1999.

Cooperativismo e agroindústria no Paraná. 2. ed. Curitiba, 1990.

O cooperativismo paranaense. Curitiba: [s.n.], 1997.

PASSOS, Carlos R. A política agrícola na década de 80. Análise Conjuntural, Curitiba, v. 12, n. 2, p. 5-6, fev. 1990.

PAULA, Nilson M. As transformações no Agribusiness no contexto da globalização. Revista Paranaense de Desenvolvimento, Curitiba, n. 91, p. 33-47, maio/ago. 1997.

PEREIRA, Laércio B. A análise da estrutura produtiva e do desempenho da agroindústria paranaense: período 1970/ 1985. Revista de Economia e Sociologia Rural, Brasília, v. 34, n. 2, p. 31-49, nov./dez. 1995.

PINHO, Diva B. Economia e cooperativismo. São Paulo: Saraiva, 1977.

TRINTIN, Jaime G. Desenvolvimento regional: o caso paranaense. A Economia em Revista, Maringá, n. 2. 1993.

URBAN, M. L. Os novos rumos da agroindústria. Análise Conjuntural, Curitiba, v. 12, n. 2, p. 1-3, fev. 1990.

VAN KAICK, Guntolf. Integração cooperativista no setor agropecuário. In: Propostas cooperativistas. Curitiba, OCEPAR, 1986, p. 7-18.

VEIGA, Alberto. Condicionantes do desenvolvimento agroindustrial. Revista Economia Rural, Brasília, v. 18, n. 2, p. 317-326, abr./jun. 1980.

VILELA, Nirlene J. Fatores desfavoráveis ao desenvolvimento do cooperativismo no Brasil. In: II SEMINÁRIO AGROPECUÁRIO DO ACRE, 2., 1998, Rio Branco. Anais... Rio Branco: Embrapa, 1998. p. 301-310.

WOSH, Luiz F. O. O papel marcante do complexo soja nas exportações paranaenses. Análise Conjuntural, Curitiba, v. 18, n. 7-8, p. 15-17, jul./ago.1996.

ZEFERINO, Augusto C. Análise da localização espacial dos investimentos. Boletim de Geografia Teorética, Rio Claro, v. 16, n. 2, p. 77-93, out. 1991. 